\title{
About the Sustainability of Buildings
}

\author{
Corneliu BOB* \\ Polytechnic University of Timisoara, Romania
}

*Corresponding author: Corneliu BOB, Polytechnic University of Timisoara, Romania.

Received Date: May 17, 2021

Published Date: June 17, 2021

\section{Opinion}

According to WCEC - Brudtland Report 1987 "Sustainable development is a development that meets the needs of the present without compromising of the ability of the future generations to meet their own needs." Sustainability is at the confluence of the three dimensions (Figure 1).

Buildings are very important industrial sector of sustainable development. The building industry represent approximately $40 \%$ of the total energy consumed. The energy used for heating and/or cooling, during the service life of a building is approximately $80 \%$ of the total energy consumed through building life cycle; $7 \%$ energy is used with row materials and contribution to energy due to demolition is 3\%. According to some studies and to the paper of Y.J.GE and H.F. Xiang (IABSE Symposium Bangkok 2009) the Pyramid of Building Sustainability is presented in the Figure 2 (Figure 2).

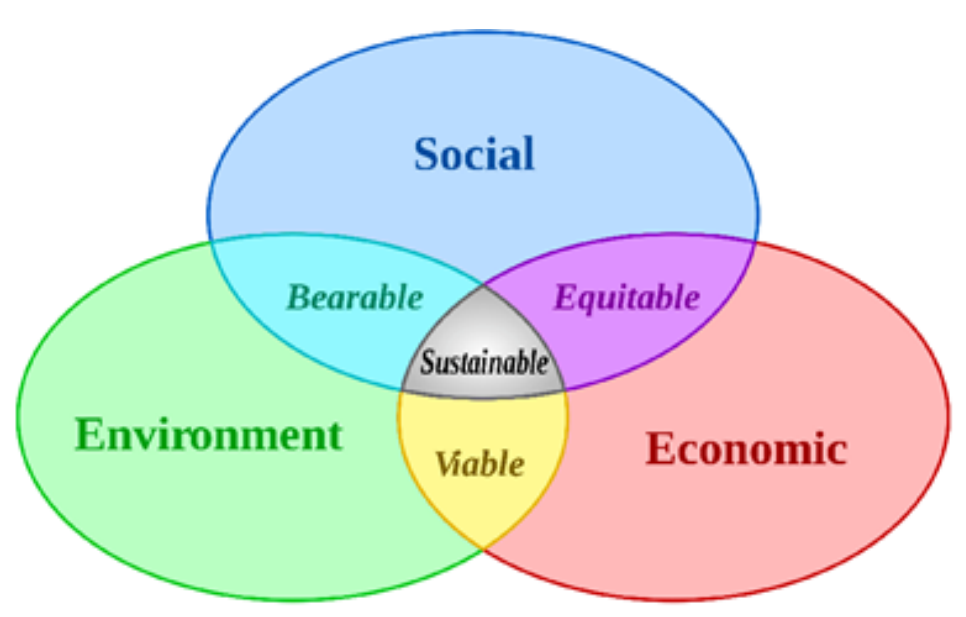

Figure 1: Sustainability at the confluence of the three dimensions. 


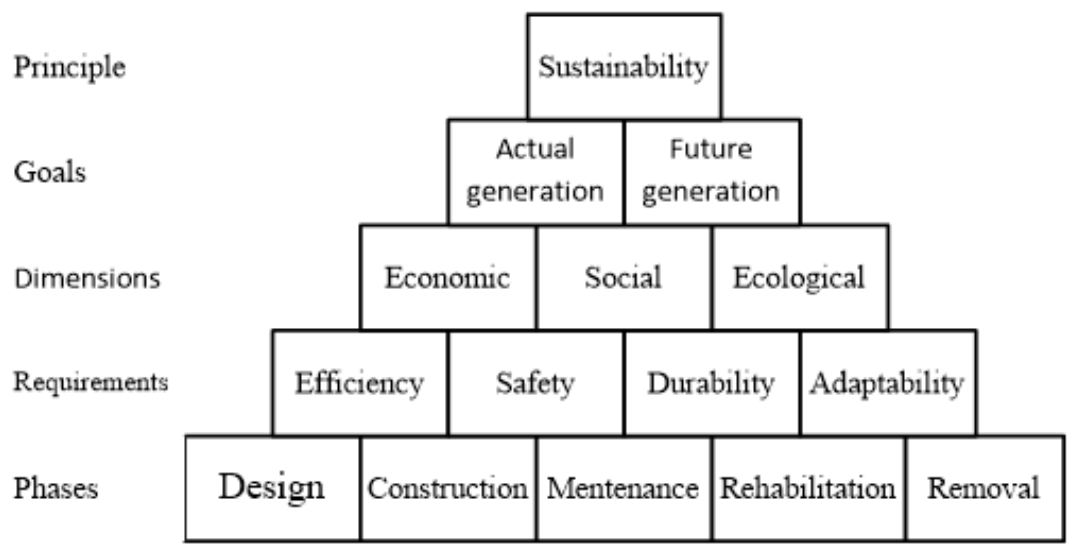

Figure 2: The pyramid of building sustainability.

Based on the author's and collaborators studies and the suggestion from the "Pyramid of building sustainability", a scheme of Building Sustainability Structure is given in Figure 3 (Figure 3).

The main sustainability concept is to design building with a long service life, low operating and maintenance costs and high energy efficiency. Many models/methods have been proposed for sustainable design as: BREEAM; LEED; CASBEE; SBTool; DGNB etc. A quantitative model for evaluating the sustainability is necessary to be established for comparison between the solution of the project of development and the planning of new buildings, as well as of strengthening of existing structures. In accordance with Figures 2 $\& 3$, a simple quantitative formula, for evaluating the sustainability index $\mathrm{S}$, was proposed by the author:

$$
\mathrm{S}=0.4 \frac{\mathrm{E}^{\mathrm{R}}}{\mathrm{E}}+0.3 \frac{\mathrm{C}^{\mathrm{R}}}{\mathrm{C}}+0.3 \frac{\mathbf{8}}{\mathbf{\delta}}
$$

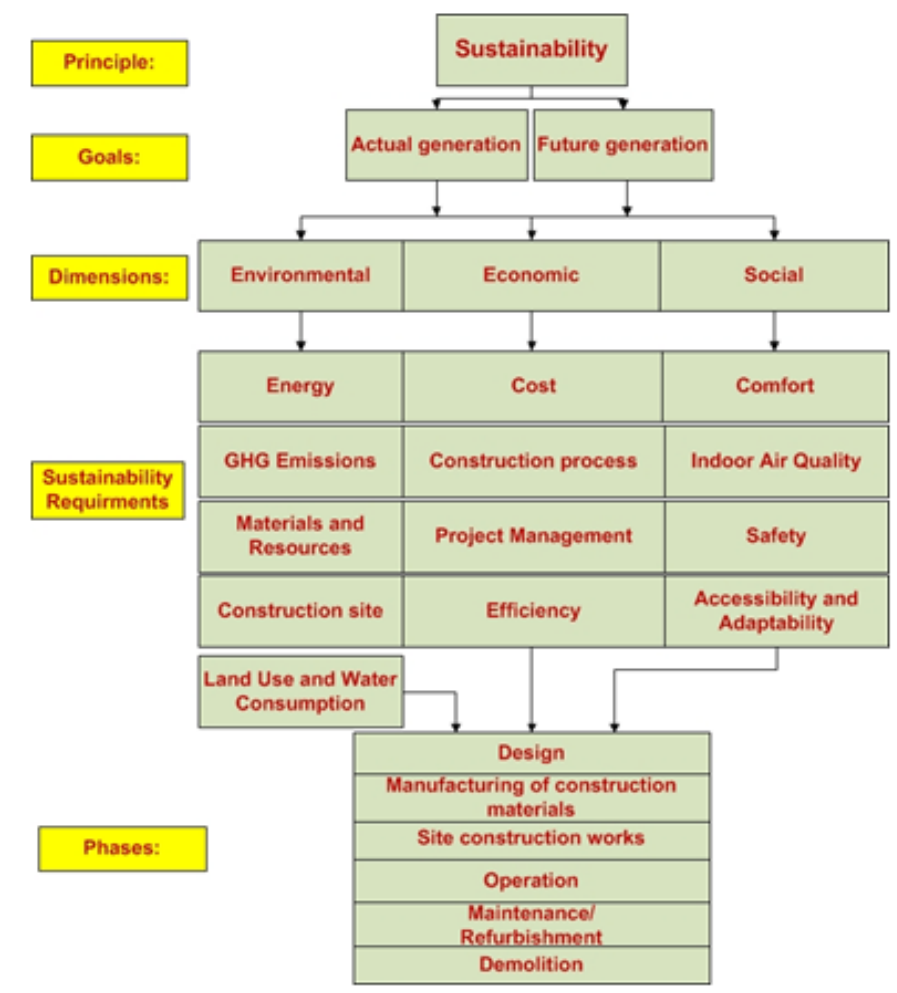

Figure 3: Structure of Building Sustainability. 
where:

E - the total energy incorporated into a building; ER - reference energy.

C - total cost of the building; CR - total cost of the reference building.

So- maximum value of a specific parameter (comfort, safety, etc) of social dimension.
$\mathrm{So}^{\mathrm{R}}$ - reference value of a specific parameter.

\section{Acknowledgment}

None.

\section{Conflict of Interest}

No conflict of interest. 